\title{
TTR
}

Traduction, terminologie, re?daction

\section{Remarks on Cultural Transfer from an LLD}

\section{Yo-In Song}

Volume 4, numéro 1, 1st semester 1991

Languages and Cultures in Translation Theories

URI : https://id.erudit.org/iderudit/037082ar

DOI : https://doi.org/10.7202/037082ar

Aller au sommaire du numéro

Éditeur(s)

Association canadienne de traductologie

ISSN

0835-8443 (imprimé)

1708-2188 (numérique)

Découvrir la revue

Citer cet article

Song, Y.-I. (1991). Remarks on Cultural Transfer from an LLD. TTR, 4(1), 63-79. https://doi.org/10.7202/037082ar d'utilisation que vous pouvez consulter en ligne.

https://apropos.erudit.org/fr/usagers/politique-dutilisation/ 


\section{Remarks on Cultural Transfer from an LLD}

\section{Yo-In Song}

\section{Introductory}

The purpose of this study is to examine the nature and implications of the process of cultural transfer from a language of limited diffusion (LLD) into a language of unlimited diffusion (LUD) ${ }^{1}$ in the context of translation theory. It is argued that cultural opacity is by no means an insurmountable hurdle in the total strategy of transfer from an LLD into an LUD or "world language."

Following Radó (1987), we say that languages belonging to the LLD category include Arabic, Chinese, Japanese, Korean, Swahili, Hungarian, Czech, Tai, etc. Likewise, we classify English, French, German, Spanish, Italian and Russian as LUDs or world languages. If we adopt Radó's suggestion that non-LUDs with more than 50 million native speakers might be classified into a third category, we might separate Arabic, Chinese, Japanese, Korean, Swahili, Hindi, Urdu, Bengali, etc., and classify them into what I should like to call "languages of intermediate diffusion (LID)." For the purpose of this study, however, the dichotomy of LUD and LLD is considered sufficient, and we may dispense with the trichotomy.

1. The term "unlimited" here should not be interpreted literally but should be taken in a pragmatic sense: "virtually unlimited." 
As an archetype of LLD used throughout this study, I have chosen Korean, my own mother tongue. The LUD will be confined to English for the sake of clarity and brevity. All this does not mean that a larger sampling from a diverse variety of languages would not be necessary or desirable. It simply means that the task of dealing with a larger body of data lies beyond the scope of this study. It is felt nevertheless that even a study of this scope can typify the problems, solutions, and implications of the seemingly untranslatable area of cross-cultural transfer in general.

As an LLD, Korean is often genetically identified as an offshoot of the Finno-Ugric or Ural-Altaic family, but there is no conclusive evidence to prove it. Like Japanese, it is an agglutinating language with its lexicon made up of two elements: the pure native stock and the stock of Chinese derivatives. It has a phonological system of its own unrelated to most other languages. The writing system is based on a phonetic alphabet (hankul) invented in the fifteenth century. Words of pure native origin are written exclusively in this alphabet. But those of Chinese origin can be written either in the Korean alphabet or in Chinese characters. Works of literary art such as novels, poems, plays, and essays are published exclusively in the Korean alphabet, but newspapers, learned journals, and non-literary books are published in either the Korean alphabet or Chinese character. Today Korean is spoken by approximately 65 million people as their native language: 43 million in South Korea, 20 million in North Korea, and two million in the Korean diaspora in the United States, Japan, China, and the Soviet Union. Native speakers of Korean now live in most major cities throughout the world. Korean is the language of the Korean people, with an unbroken history of 5,000 years except for the recent 35-year annexation by the Japanese empire. It is as complex and functional as any other language in the world.

Before proceeding any further, it would be appropriate to define the term "culture" used throughout this study. "Culture" is a word that could be defined in a variety of ways. But for the purposes of this study it is defined as "the civilization of a people, especially at a certain stage of its development or history" as was done by the Oxford English Dictionary (1933, Supplement). Defining it in this broad sense has its advantages. For one thing, it is at once pervasive and inclusive. For another, it obviates the need for an explanation in each instance of its use. 
A useful typology of translation in the discussion of cultural transfer from an LLD would be one based on the direction of translation. Thus, a translation, when the target language is the translator's own native language, may be said to be involved in "inbound translation," whereas one whose source language is the mother tongue may be described as being engaged in "outbound translation." A third category involves the translator for whom neither the source language nor the target language is his own native language. In other words, he translates from a foreign language into yet another foreign language. This would be called "crossover" translation (Song, 1975, pp. 5-6). In the case of an LLD like Korean, "crossover translation" is an extremely rare phenomenon. Cultural transfer is almost unthinkable for a "crossover" translator. The number of "outbound" translators who translate from Korean is greater than that of "inbound" translators. Only a handful of inbound translators are active in the United States, Great Britain, Germany, France, and the Soviet Union, so far as LUDs are concerned.

The term "outbound translation" is equivalent to what Radó calls FMT (from-mother-tongue) translation (Radó, 1987). It sounds less clumsy and more concise than the latter. Then, too, the term "national translator" is often confusing, if not misleading. For it means an indigenous or local translator who translates either from or into his native language. The term "outbound translation" stands for unidirectional (native-to-foreign) translation as does the term "inbound translation" (foreign-to-native). This study has adopted "outbound" and "inbound" translation or translator wherever the distinction has to be made.

The following section will deal with the problem of linguistic and cultural diffusion. The penultimate section will take up what I call "the ethnocultural pentad" to examine the nature and function of cultural transfer from Korean. The final section will seek to find out what implications such a process has in translation theory. ${ }^{2}$

2. Cf Danielson (1982): "... the essence of translation is the encounter and interchange between languages and their cultures". 


\section{Linguistic and Cultural Diffusion}

It is a commonplace that language and culture do not go hand in hand when it comes to diffusion. A language may belong to a proud culture and a great tradition of written literature. It may be spoken by a vast number of people as their mother tongue. Its classics may be known, albeit through translation, throughout every civilized corner of the globe. The prime example is Chinese. But only a negligible minority of people outside China know enough English to converse in, much less write in it, and the degree of its diffusion is markedly limited.

Today English is said to be a language of maximum diffusion in that it is a first language to more than 400 million people in three continents of the world. It is spoken as a second language by more than 400 million people. Thus nearly a fifth of the people of the entire world have a varying degree of knowledge of it. When this is compared with Chinese, the latter is numerically superior since at least a quarter of the world's population speak it as their mother tongue. And yet English enjoys an incomparably greater influence than does Chinese in terms of cultural sophistication, science and technology, economy and government, and nearly all other fields of human endeavor.

When it comes to cultural diffusion, Chinese culture is decidedly inferior to English simply because not enough of its impact is felt overseas to overtake English. This is true despite the fact Chinese culture is a more ancient one with a vastly more enriching storehouse of knowledge than English culture. This proves that mere number of speakers or greater historical tradition does not ensure a corresponding degree of diffusion throughout the world. Japanese culture is by far the less influential than either Chinese or English culture. The number of speakers of Japanese as a first language is incomparably smaller than that of Chinese or English. The Japanese today may be rated as one of the most advanced nations in the world in terms of science and technology, economic development, governmental maturity, and cultural sophistication. Yet their culture as a whole is substantially less influential than that of Anglo-Americans. Japanese culture enjoys a far less significant degree of diffusion than Anglo-American culture. When it comes to Korean culture, it is even more limited as far as worldwide diffusion is concerned. The fact that Korea has 4,000 years of unbroken history except for the 35-year rule of Japan in 
the twentieth century and that she had movable type long before Gutenberg does not improve the situation.

A culture can be more "complex" or "dominant"; "simple" or "subordinate" than another or it can lie somewhere "in between" or "intermediate." Thus the axiom can be stated: cultural complexity or dominance does not necessarily enhance linguistic diffusion and vice versa; nor does the size of a population enjoying varying degrees of cultural development have anything to do with linguistic diffusion. Korean culture is by no means a simple one and the Korean population is a fairly large one when viewed on a global scale, and yet neither is this culture considered dominant nor can the Korean language avoid being dubbed an LLD. Other examples abound in America or Europe. German, French, Spanish, Italian, and Russian are LUDs, but the number of their speakers is not the cause of their being LUDs. Their cultures are not necessarily more complex than Chinese culture, and yet they are considered complex or dominant. Historically, Chinese culture has had an impact in Asia as influential as the Greco-Roman culture has had in Western Europe. But, here again, when viewed on a global scale, Chinese culture is regarded as comparatively simple. The key word is "the global scale." Measured on the Asian, especially the Far Eastern scale, Chinese is an LUD and the culture is a complex one. Elsewhere, French is a culturally complex language with unlimited diffusion. The fact that the French population is dwindling does not alter the situation, for there is an increasing number of non-French French speakers worldwide today. A mere combination of population and language does not lead to cultural or linguistic diffusion. A great many factors no doubt intervene to make a language an LUD or LLD as the case may be, and to make a culture complex or dominant; simple or subordinate as the case may be.

\section{The Ethnocultural Pentad and Translation}

\section{Communicability and Translatability}

Translation theory must start from the premise that perfect communication is an unthinkable goal. A theory of cross-lingual transfer

3. The word "subordinate" in this context is not value-oriented. 
that does not take this fact into account is doomed to failure. ${ }^{4}$ Interpersonal communication can never be perfect, nor can we expect it to be. Perfect communication is an elusive goal even among the speakers of the same mother tongue. As de Waard and Nida (1986, pp. 42-44) pointed out, there is always some loss in communication even between two scholars talking about something in their area of particular competence. De Waard and Nida stated that even in this case the loss may be at least twenty percent. Thus some loss in translating from one language into another is to be expected.

What all this means is that communication in whatever mode - intralingual, interlingual or intersemiotic - is at the very best only eighty percent successful even among the monolingual native speakers of the same language. Therefore, a translator works from a source language message that conveys less than eighty percent of the original. Thus even the best translation cannot exceed eighty percent of the communication content of the source language message. This gives us the simple arithmetic of 64 percent as being the maximum achievable goal in the target language. This is an important factor in any discussion of fidelity in translation. Information loss is the prime reason that communication is inevitably imperfect (Catford, 1965, p. 102). What the translator should try to do is to keep such loss at a tolerable minimum.

All messages are culture-sensitive. We might go so far as to say that even a chemical symbol like $\mathrm{H}_{2} \mathrm{O}$ is in some way, albeit minutely, culture-sensitive. One man's $\mathrm{H}_{2} \mathrm{O}$ might be transparent liquid in a glass tube while it could well be another's wet solution in a bottle of glass, ad infinitum.

When it comes to a word like mother-in-law, for instance, Koreans' "mother-in-law" (cangmos) invokes an emotive response partly different from that aroused by the English word. The outbound translator, whose native language is the source language,

4. Wilss (1982, p. 218) notes that "neither psycholinguistics nor neurology can as yet provide reliable information on how matching procedures take place."

5. The Korean words in this study are romanized according to the Yale Romanization System for Korean. 
is thoroughly familiar with such a response, hence he needs to become familiar with the target language culture involving the term. This is why linguistic transfer alone is not an adequate translation. The cultural connotation which inherently accompanies the source language item must somehow be transferred into the target language text. This is not an impossible task. Cultural sensitivity on the part of the translator is a sine qua non, needless to say. But what he actually does in the ethnocultural transfer process is at his discretion. Whatever he does, of course, runs the risk of losing too much of the original author's intention (Nida and Rayburn, 1981, pp. 1-4). But then the word is never given up as being completely intractable.

\section{The Ethnocultural Pentad and Translation}

Whether inbound or outbound, the translator can ill afford to be ignorant of the ethnology of the source language culture or the target language culture whichever the case may be, including their ethnography of speaking and speaking rules. The totality of a culture consists of five major dimensions, which I have chosen to call the ethnocultural pentad. The five dimensions are: a) the Cosmogonic-ecological Dimension; b) the Bio-physiological Dimension; c) the Psycho-physical Dimension; d) the Socio-institutional Dimension, and e) the Techno-scientific Dimension. ${ }^{6}$

\section{a. The Cosmogonic-ecological Dimension}

Since all humans inhabit the same planet, the notions of cosmogony and ecology should be common to all languages and cultures. Thus we may include the following elements under the category of the cosmogonic universals: cold, heat, rain, wind, earth, sun, moon, star, flora and fauna, minerals, planetary divisions of time such as day and night, time or parts of day, month, solar and lunar years, cycle of vegetation, and meteorological or climatic change. Korean culture entertains different mythological, superstitious or folkloristic notions about some or all of their elements from the way LUDs do. Some of them may be identified with supernatural deities. But this does not invalidate the existence of universals

6. The ethnocultural pentad is an expansion cum modification of the quadripartite division of the Weltanschauung as described in Song (1984, pp. 29-37). 
where humans of any race or creed inhabit. In both Korean and English the sun is a fertile source of myths, superstitions, and folk tales. The Koreans even personify and accord a honorific status to it by calling it haynim ("the honorable sun"). Yet they are no different from English and other LUD speakers in perceiving that "the sun rises and sets."

Some of the metaphorical expressions involved in this dimension are directly transferable, such as chakewun nwuncholicold stare; kamcengui yelki-heat of passion; insayngui pom-spring(time) of life, etc. There are others that do not lend themselves so easily to direct transfer, such as kunye-nun palami natta-She has wind stirred (she has grown sexually aware); kwwisin-i kokul hantaThe devil bewails (The devil may be shocked.), etc. In all these non-directly transferable cases, difficulties do exist in one context or another. But the solutions are by no means unavailable. Most can be paraphrased in LUDs; some can be loan-translated (in calque forms), others can be footnoted, and still others can be transliterated if the context makes the meaning clear enough. Thus in LLDs like Korean, the expression hay-ka ppalli kanta - The sun goes fast does not betray astronomical ignorance on the part of the Koreans. It only means that daylight is getting short.

The Korean flora like kae-salku.("dog apricot"), and fauna like kwulengi ( 2 non-LUD item) can be paraphrased in English as wild apricot and yellowish brown serpent, respectively. Furthermore, if it is necessary to be more specific or exact, their botanical or zoological names can be found. But in works of literature merely saying apricot or snake or serpent would be sufficient in most instances. Again the metaphorical expression ku-nun kulengita can be rendered as he is a wily and crafty fellow. ${ }^{8}$ Countless other uses of animism, pantheism and personification in LLDs like Korean can be transferred into LUDs like English in one way or another. This is because everywhere on earth human beings share a common core of experience and mere differences of surface expression does not pose an insurmountable hurdle in any crosscultural transfer. In short, no culture-sensitive word, phrase, sentence - idiomatic, metaphorical, metonymic or other wise - in an

7. See Song (1988) for an analysis of nim as an honorific suffix.

8. See Nida's box-car analogy (1984, pp. 132-133), which may apply to syntax as well. 
LLD like Korean should be an untransferable entity in an LUD like English.

\section{b. The Bio-physiological Dimension}

The bio-physiological dimension is a necessary corollary of the fundamental similarity in the biological evolution of mankind and in the conditions of life on our planet. It encompasses six biophysiological functions: nourishment, drinking, respiration, sleep, excretion, and procreation. There are certain semantic fields which are directly related to the perception of the world, independently of any conceptual organization. The sensory perceptions, which may be visual, auditory, olfactory, gustatory or tactile, belong to this category. Anatomical characteristics, physiological cycles, and diagnostic terms ${ }^{9}$ or terms describing physical symptoms may constitute a substratum of the set. Likewise, somatic responses to temperature changes, sexual stimuli, hunger, thirst, and so on constitute an additional substratum.

In Korean as well as in English "love" is a sentiment associated with the "heart," but its equivalent in Karre, an LLD in French Equatorial Africa, is the "liver"; that in Conob, a Mayan LLD of Guatemala, it is the "abdomen"; and in Marshallese, an LLD in the South Pacific, it is the "throat" (Nida, 1975, p. 176). These are culturally conditioned features that diverge from the substrata. Similarly, the relatively abundant diagnostic and gustatory terms in Korean vis-á-vis English may be regarded as culturally conditioned divergences. But, again, this does not invalidate the fundamental similarity of somatic responses across racial, ethnic or national borders. An American who tastes Korean kimchi for the first time, for example, can usually convey his gustatory experience in one fashion or another, such as, "It tastes like sauerkraut." It appears that a modicum of ethnographical knowledge is all that is necessary to transfer these culture-sensitive items from an LLD into an LUD.

Finally, the bio-physiological process of birth, aging and death constitute another important substratum. Here again Korean and English are remarkably alike in cutting up the human's aging process into infancy, boy or girlhood, youth, adolescence, adulthood, and old age. The ritual customs and practices associated

9.

The Koreans' diagnostic terms are proverbially plentiful. 
with birth, aging and death in Korea are, however, nothing like the Judeo-Christian notions of America and Europe where LUDs are spoken. For instance, in rural Korea a baby's birth is marked by offerings as well as rice ropes adorned by strips of white paper and charcoal pieces (for a girl baby) and charcoal and pepper (for a boy baby). There are terms unique to the LLD of Korea, but they are not untransferable if footnoting or paraphrase is adopted. The Korean goes through the 100th day (paykill) after his birth, his first birthday and 60th birthday (hwankap) in old age with festive celebrations. These culture-sensitive terms as translated verbatim here are by no means opaque to an LUD speaker. If need be, an adjective like festive might clarify their ethnocultural significance. The Koreans have an elaborate custom of burial and after-death rites, each having its own culture-sensitive terminology. To do justice to them requires an adequate knowledge of ethnology concerning traditional Korea's folkways, customs, mores and conventions. An interesting item worth knowing is the fact that Koreans use the idiomatic phrase cwuktolok (till death; to the extent of death) to describe a broader range of experience as an intensifier than do Americans or Britons. Thus a Korean may say he is happy to death; angry to death, hungry to death, pleased to death, grief-stricken to death, ad infinitum. Some of these are directly transferable into an LUD like English, but some are not. Nevertheless, solutions are readily available in the form of paraphrase or circumlocution. The Korean expression, nayil moley-ka naui hoekapio ("Tomorrow or the day after tomorrow is my birthday") in most instances is rendered as, $I$ will celebrate my sixteenth birthday in a day or two. ${ }^{10}$

The bio-physiological dimension having so much to do with our own physical being, is perhaps easier to handle than the cosmogonic-ecological dimension. But it has a wealth of metaphorical and metonymic experiences that require ethnological as well as cultural knowledge on the part of an inbound culture or the LUD culture, whichever the case may be. Translatability is not impaired in all cases.

10. Mounin (1963) has gone so far as to entitle one of his chapters as "L'ethnologie est une traduction." 


\section{c. The Psycho-physical Dimension}

The psycho-physical dimension is more complex than the foregoing because a marked degree of conceptualization comes into the picture. It includes spatio-temporal designations, numerals, color terms, metaphors and other figures of speech, and other concepts related primarily to psychology and the physical world. The fact that the Korean people use one set of spatio-temporal measures and the Americans another does not prove that the former cannot understand the spatio-temporal units used by the latter or vice versa. The Korean unit of distance $l i$ can be rendered metrically as four kilometers while the American mile can be conceived of as 1.6 kilometers. That this presents no serious problem was well demonstrated during the Korean War in which the Korean and American troops staged countless successful joint operations, using the metric system. Whereas the English language may have the special term fortnight for two weeks, the Koreans have the separate term polum for fifteen days. But no serious problem arises in rendering fortnight as icwu-il ("two weeks") or in translating polum as half month or fifteen days.

The case of the numerals needs some further comment. Boas (1911, pp. 59-73) declared that there is no proof that the lack of the use of numerals is in any way connected with the inability to form the concept of higher numbers." tioned divergences in the use of numerals normally involve sets of numbers like "dozen," "score," and "teen" (as in "teenager"). Here again, no serious difficulty arises in ordinary circumstances in rendering "siptay" ("those ten to nineteen years old") as teenagers in English. If there is a context in which the addition of three years makes a crucial difference, the translation can be rendered as youth in the ten to nineteen-year age group. Similarly, the Korean term han phaswu given as a five-day period could hardly inconvenience any speaker of an LUD.

The case of color terms has been well presented by Berlin and Kay (1969). There is no need to say anything further than their universalistic approach. The problem of the color category is

11. The figure "ninety-nine" is the highest that the modern native Korean language can handle, but the size of Chinese derivatives enables its speakers to cope with astronomical figures like co (trillion) quite effortlessly. 
not an intractable one even though its gradations may range from 7.5 million to 10 million (Conklin, 1955). The fact that the Koreans say phulun hanul (blue sky) and phulun san (blue mountain) does not mean that they cannot distinguish between "blue" and "green," but that they do not care to do so, for they can say loksayk-ui san (green mountain) if the need to do so arises. Korean has decidedly more gradations of "red" than English, but the English language can manage in one way or another without too much difficulty.

Of particular interest to the translation theorist are anthropomorphic metaphors, parallel metaphors and metonymics. The associations on which they are based seem to be deeply rooted in human experience and largely independent of culture and environment. In all languages the majority of expressions referring to inanimate objects are formed by transfers from the human body and its parts, from human senses and human passion. Ignorant man makes himself the yardstick of the universe (Ullman, 1963, p. 241). Both Korean and English rely on anthropomorphic metaphors to a great extent. Korean uses "eye," "nose," "ear," "mouth," and "hand" most frequently while English takes advantage of "hear," "head," "hand," "leg," and "face" most frequently. Here the LLD poses no cultural transfer problem to the LUD. The "ear of a needle" in Korean may strike the American reader as being outlandish but by no means is it opaque. When a Korean says that "someone's mouth is heavy," the LUD listener must know that "he is careful of what he says." A bit of ethnographical knowledge would be needed here. ${ }^{12}$

In the case of parallel metaphors like the LUD item "grasp," the LUD speaker may say that he can "grasp" the meaning of a passage as well as "grasp" an object, but the LLD speaker can "grasp" an object but not the meaning of a passage. All the same, the LLD may say putchapta ("catch hold of") in the latter case and may not be opaque to the LUD listener although it may sound awkward. In the case of metonymic associations like "tongue" in English meaning both "body part" and "language," in Korean it can only mean "body part" and not "language". But this raises no problem of transfer from the LLD. Elsewhere items of synesthesia

12. Roothaer (1978) places the translator somewhere in the middle between the interpreter of cultural differences and someone who leaves interpretation to his readers. 
in Korean like "warm reception," "cold reception," and "loud color" are the same as in English. All in all, the psycho-physiological dimension constitutes no serious problem of transfer from an LLD into an LUD.

\section{d. The Socio-institutional Dimension}

The socio-institutional dimension is undoubtedly the most susceptible of cultural conditioning. It includes kinships, familial systems, taboos, value systems, customs and mores, social structures and institutions, and all other phenomena related to the self-other orientation of a people. Religion, education, economy and government are heavily institutionally oriented.

No matter how complex the manner in which the Koreans may classify their kinships, it bears a fundamental similarity to the way the Anglo-Americans categorize their kinships in that both share the identical nuclear family structure to begin with. While the Koreans are particular about the relative age of their family members, the Americans are conscious of their sex. Both nations have essentially patrilinial family structures. The Koreans' imopu may be rendered as maternal uncle's husband to be exact or merely as uncle if the context allows. Ancestor worship may be practiced by the Koreans to a degree hardly known in the Anglo-American culture. Thus sengmyo may connote something more than just "visiting" one's ancestral tombs. But it does not invalidate the translatability of the Korean ritual. ${ }^{13}$

Verbal taboos in both the LLD and the LUD are essentially alike in that they fall under these categories; namely fearinspired taboos concerning God or Heaven, the dead, the evil spirits, and certain animals; delicacy-inspired taboos related to illness, death, physical and mental deficiency, stealing and killing; and decency or propriety-oriented taboos regarding sex, certain body parts and functions and swear-words (cf. Ullmann, 1963, p. 245). The scatological terms are not taboos in the LLD. The expletive hell (ciok) is used by the LLD in all contexts. The monosyllabic sexual taboos in both cultures are not taboos when replaced by non-monosyllabic terms.

13. The Koreans have a more elaborate system of ancestor-worship rites than the Anglo-Americans. 
The unmentionability of the personal names of certain family members on the part of the younger, lower generation, or female relatives in Korean culture is not to be found in American culture. But there is always a translational device or two to take care of this problem. The practice of first-naming their senior business colleagues, older acquaintances, older relatives, and others is impossible in Korean. Translating this into English nevertheless is not an intractable task. The honorific tag may be either deleted or neutralized.

The misogynous elements in the Korean folklore and superstition presents an interesting case to the translator. Instances in which "woman" is identified with bad luck, outnumber those connoting good luck at least five to one (e.g., "If you see a woman in your dream, you're out of luck" vs. "If a woman has big feet, she will be dearly loved by her husband"). But misogyny is not a monopoly of the LLD, and a translation is readily available. The Koreans' "inscrutable smile" concealing anguish or enmity and the Americans' shrugging of the shoulders to indicate a variety of responses can all be taken care of with a bit of contextual cushioning. These semi-linguistic, paralinguistic or exolinguistic signs require some ethnocultural knowledge on the part of either an inbound or an outbound translator. But they are always translatable in one way or another.

Finally, in the proverbial expressions of Koreans, the words kay (dog), totuk (thief), and casik (offspring) ) $^{34}$ are most frequently featured. In the Anglo-American culture the most frequently used items are dog, devil, and foot. Thus, proverbs do not constitute translational opacity in the case of Korean vs. English, so long as the translator is ethnoculturally oriented. Chitnun kay-nun mulci annun-ta is rendered almost literally as Great barkers are no biters.

\section{e. The Techno-scientific Dimension}

Not much needs to be said about the techno-scientific dimension. Korean uses the technological and scientific terminology imported from English and a few other LUDs plus some Chinese derivatives. What translation involves in most cases is back translation. Some

14. The word casik-offspring, used literally as well as figuratively, is a uni-sexual term. 
of the terms do not even require back translation as in computer, television, jet, etc, but may be simply be directly transferred back. There are cases, however, where the original English words have been skewed or mangled in Korean, such as limokhon (remote control) and sutteyng (stainless steel). The Korean lexicon contains more than ten thousand loan words from English and a few other LUDs, and many of them are related to science and technology.

The techno-scientific dimension is by no means intractable in all instances. It is steadily expanding as science and technology keep developing rapidly from day to day. The LLD keeps borrowing to keep abreast of the times even at the cost of interlarding itself with alien words. Cultural transfer from an LLD like Korean in the area of science and technology is as easy as it was when the lexicon was originally borrowed.

\section{Concluding Remarks}

Language and culture do not go hand in hand; their boundaries do not overlap. The language of a complex culture like that of China may have the largest number of native speakers in the world, and yet it is an LLD. English is the language of a complex culture spoken natively by a smaller number of people than Chinese, and yet it is an LUD. A language like Korean, spoken natively by approximately 65 million people who possess a complex culture, is an LLD. In examining the nature and implications of the process of cultural transfer from an LLD like Korean into an LUD like English, the totality of culture is broken down into what may be called the "ethnocultural pentad." The five dimensions which make up the pentad are: the cosmogonic-ecological dimension, the biophysiological dimension, the psycho-physical dimension, the socioinstitutional dimension and the techno-scientific dimension.

This study has confirmed the translatability from Korean into English of major categories in these dimensions. Some of the lexical, phrasal, or sentential items in the LLD appear untransferable, but they have been determined to be by no means intractable. Translational devices such as direct transfer, paraphrase or circumlocution, loan translation or calque, transliteration, and footnoting can be mobilized to tackle the cross-lingual as well as cross-cultural problems that may arise (Newmark, 1981 pp. 30-32). The implications of all this are that such a situation may apply to other instances of LLD-to-LUD cultural transfer with equal validity. 
The cultural features of an LLD like Korean are transferable essentially because its native speakers share a common core of experience with the native speakers of English since they share the same planet. Translation theory must take this fact into account if it is to be tenable.

\section{References}

BERLIN, B. and Kay, P. (1969). Basic Color Terms. Berkeley and Los Angeles, The University of California Press.

BOAS, Franz (1911). Linguistics and ethnology, in Boas, ed., Franz. Handbook of America Indian Languages, pp. 59-73.

CATFORD, J.C. (1965). A linguistic Theory of Translation. London, Oxford University Press.

CONKLIN, Harold C. (1955). "Hanoono color categories." Southwestern Journal of Anthropology 11, pp. 339-344.

DANIELSON, J. David (1981). "Translation: from otherness to complementation." Quinquereme, Vol. 5, No. 1, pp. 1-17.

DE WAARD, Jan and Nida, Eugene A. (1986). From One Language to Another. Nashville, Thomas Nelson.

GREENBERG, Joseph H. ed. (1963). Universals in Language. Cambridge, Mass., The M.I.T. Press.

MOUNIN, Georges (1963). Les problèmes théoriques de la traduction. Paris, Gallimard.

NEWMARK, Peter (1981). Approaches To Translation. Oxford, Pergamon Press Ltd.

NIDA, Eugene A. (1975). Exploring Semantic Structures. München, Wilhelm Fink Verlag. 
(1984). Signs, Sense, translation. Capetown, The Bible Society of South Africa.

NIDA, Eugene A. and Reyburn, William (1981). Meaning Across Cultures. Maryknoll, N.Y., Cris Books.

RADÓ, György (1987). "A typology of LLD problems." Babel, 33 , pp. 6-13.

ROOTHAER, Roger (1978). "Language, thought and translation." Babel, 24, pp. 130-135.

SONG, Yo-In (1975). Translation: Theory and Practice. Seoul, Dongguk University Press.

(1984). Topics in Translation Studies. Seoul, Hanshin Publishing Company.

(1988). "Some transemic characteristics of nim." Dongguk Review, 16, pp. 101-108.

ULLMAN, Stephen (1963). "Semantic universals." In Greenberg ed., Universals in Language, pp. 217-262.

WILSS, Wolfram (1982). The Science of Translation. Tübingen, Gunter Narr Verlag. 